\title{
IMPLEMENTASI SISTEM VOUCHER DENGAN ROUTER MIKROTIK
}

\author{
${ }^{1}$ Whisnumurti Adhiwibowo, ${ }^{2}$ Wijatmoko Mindatama \\ ${ }^{1,2}$ FakultasTeknologi Informasi dan Komunikasi - Universitas Semarang \\ I'whisnu@usm.ac.id, ${ }^{2}$ mindatama@gmail.com
}

\begin{abstract}
Voucher system is a feature owned by Mikrotik to facilitate network administrators to manage access on the router based on bandwidth allocation, website filtering and access time settings. This final project will be implemented voucher system at PT. Tunggul Sakti Sejahtera. The number of employees is approximately 25 employees at headquarters who own a smartphone and connect to the company's Access Point. Bandwidth allocation, website filtering and access time setting for each employee can not be limited. To solve the problem, the authors plan to implement a voucher system on the network of PT. Tunggul Sakti Sejahtera.Implementation method of voucher system used is CISCO Network Cycle PPDIOO method has Prepare, Plan, Design, Implement, Operate, and Optimize. Implementation of voucher system at PT. Tunggul Sakti Sejahtera uses router Mikrotik Routerboard 750 series and D-Link access point as a repeater device. Voucher system can optimize network management at PT. Tunggul Sakti Sejahtera so it can facilitate network administrator in managing computer network. Documentation of system is done periodically, if the system crashes it can be restored.
\end{abstract}

Keywords: Voucher System, Mikrotik Router, PPDIOO Network Cycle.

\section{PENDAHULUAN}

Semakin berkembang teknologi informasi seperti internet berdampak kebutuhan komunikasi dan informasi seluruh lini bisnis perusahaan semakin meningkat. Dampak positif perkembangan internet adalah kemudahan komunikasi dalam mencari informasi sehingga profit perusahaan dapat meningkat. Sedangkan dampak negatif salah satunya mengakses website yang tidak berhubungan langsung dengan perusahaan menggunakan koneksi internet perusahaan oleh karyawan menggunakan smartphone pada saat jam kerja[1].

PT. Tunggul Sakti Sejahtera adalah dealer resmi penjualan motor Honda memiliki jumlah tenaga kerja 25 karyawan terdiri dari 1 kepala cabang, 1 supervisor akunting, 6 staf akutansi dan pajak, 3 supervisor operasional, 3 staf operasional, 2 frontdesk, 2 couter girl, 4 sales, 2 driver, dan 1 office boy. Karyawan dengan jabatan kepala cabang, supervisor, dan staf memiliki fasilitas komputer atau laptop yang terhubung ke jaringan internet perusahaan melalui media kabel dan non- kabel (wireless) sebagai sarana pendukung operasional. Fasilitas lain yang diberikan oleh perusahaan adalah koneksi internet melalui media non- kabel (wireless) sebagai sarana komunikasi antar karyawan menggunakan smartphone. Koneksi internet perusahaan menggunakan dua ISP berbeda yaitu MNC Play dengan layanan kecepatan akses internet up to $7 \mathrm{Mbps}$ dan Telkom Speedy dengan layanan kecepatan akses internet up to $1 \mathrm{Mbps}$. Konfigurasi yang sudah ada pada router perusahaan menggunakan fail over pada jaringan internet dan pembatasan akses internet melalui media non- kabel (wireless) hanya menggunakan Access Point Password dan mac address filtering.

Pembatasan akses internet melalui media non- kabel (wireless) [2] menggunakan Acess Point Password dan mac address filtering [3][4]berdampak karyawan masih bebas mengakses website media sosial dan website lain yang tidak berhubungan langsung dengan perusahaan. Dampak lain yang timbul adalah kecepatan akses internet menjadi tidak stabil karena pembagian akses internet yang tidak merata, serta kinerja dan produktifitas karyawan menurun. Saat ini akses internet melalui media non- kabel (wireless) dibatasi kepada karyawan dengan jabatan supervisor dan kepala cabang. Hal ini dikeluhkan sebagian staf pelaksana 
karena tidak mendapatkan fasilitas akses internet melalui media non- kabel (wireless).

Solusi permasalahan tersebut adalah dengan menerapkan sistem voucher pada router Mikrotik. Dalam sistem voucher pembatasan akses internet perusahaan digolongkan berdasarkan jabatan karyawan. Setiap jabatan mempunyai fasilitas hak akses tertentu yang sudah diatur berdasar jangka waktu akses, kecepatan akses, dan website akses sesuai kebutuhan perusahaan.

\section{Metode Penelitian}

Setelah melakukan analisis terhadap kondisi jaringan internet yang ada di PT. Tunggul Sakti Sejahtera selanjutnya dilakukan implementasi sistem voucher. Dalam perancangan sistem voucher, peneliti menggunakan metode PPDIOO [5] (Prepare, Plan, Design, Implementation, Operate, Optimize) network cycle. PPDIOO network cycle adalah metode pengembangan versi CISCO digunakan untuk mendefinisikan siklus layanan kebutuhan jaringan. Metode ini memiliki 6 tahapan proses yaitu persiapan (prepare), perencanaan (plan), desain (design), implementasi (implementation), operasional (operation), optimisasi (optimize).

Tahap prepare peneliti melakukan observasi dan berkomunikasi dengan melakukan wawancara kepada kepala instansi tentang proses bisnis dan kondisi jaringan yang sudah ada. Dalam tahap ini dilakukan pengumpulan data yang dilakukan dengan cara observasi. Hasil dari pengamatan langsung terhadap sejumlah perangkat smartphone, ketentuan hak akses internet, dan tata letak Access Point yang dijadikan bahan acuan di lingkungan PT. Tunggul Sakti Sejahtera. Pengumpulan data juga dilakukan dengan wawancara dan tanya jawab untuk memperoleh gambaran dan penjelasan mengenai kondisi jaringan internet yang ada di PT. Tunggul Sakti Sejahtera.

Tahap plan dilakukan pemetaan kebutuhan pelaksanaan pengembangan jaringan baru dan rencana anggaran yang dibutuhkan berbasis sistem voucher. Tahap design dilakukan desain topologi jaringan dan menyiapkan rencana instalasi jaringan sesuai kebutuhan. Tahap implement dilakukan pengecekan instalasi pengkabelan, memastikan seluruh proses sudah sesuai dengan desain dan melakukan konfigurasi sistem voucher. Tahap operate dilakukan kegiatan pengamatan pada jaringan komputer dan memastikan system voucher digunakan sesuai kebutuhan. Tahap optimize peneliti memprediksi dan meminimalisir masalah dan kegagalan yang akan terjadi pada jaringan. Gambaran tahapan metode PPDIOO network cycle terdapat dalam gambar 1

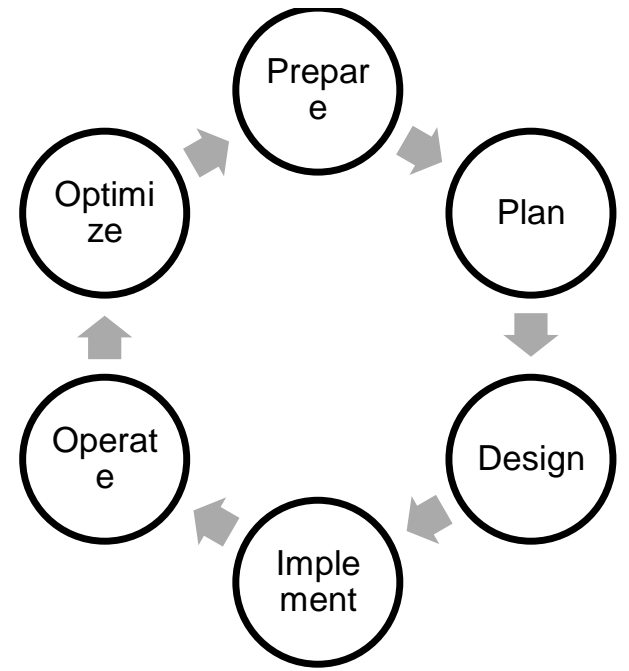

Gambar 1 Metode PPDIOO network cycle[5]

\section{HASIL DAN IMPLEMENTASI}

\section{Prepare}

Pada tahap ini peneliti melakukan observasi dan berkomunikasi dengan melakukan wawancara kepada kepala instansi PT. Tunggul Sakti Sejahtera tentang proses bisnis dan kondisi jaringan yang sudah ada di PT. Tunggul Sakti Sejahtera. Hasil observasi dan wawancara tersebut berupa kebutuhan dan pengembangan sistem voucher pada jaringan komputer yang akan diimplementasi di PT. Tunggul Sakti Sejahtera. Topologi fisik pada Arsitektur jaringan yang sedang berjalan terdapat dalam gambar 2

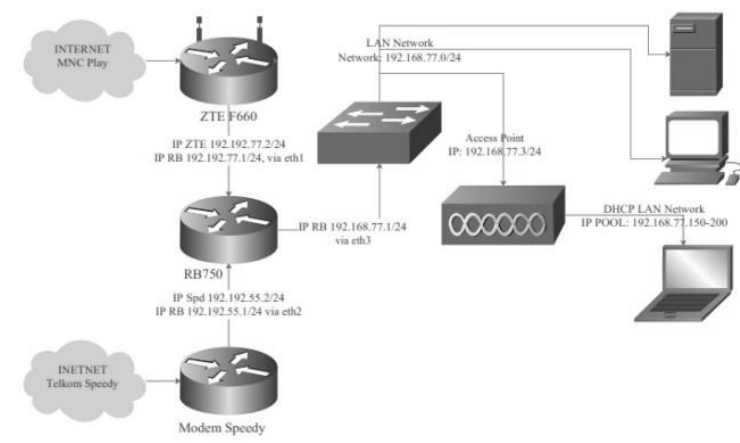

Gambar 2 Arsitektur jaringan yang sedang berjalan

Arsitektur jaringan yang sedang berjalan pada gambar 2 menggunakan 3 router dengan 2 
Pengembangan Rekayasa dan Teknologi, Vol 15, No. 2, Desember 2019, pp 118-123

p-ISSN: $1410-9840 \&$ e-ISSN: $2580-8850$

http://journals.usm.ac.id/index.php/jprt/index

ISP memiliki konfigurasi fail over dan jaringan LAN dikonfigurasi dengan network 192.168.77.0/24 memiliki static address dan DHCP address dengan pool 192.168.77.100192.168.77.200.

\section{Plan}

Pada tahap plan (perencanaan) peneliti melakukan pemetaan kebutuhan peralatan, perangkat keras, dan konfigurasi perangkat lunak baru yang dibutuhkan untuk desain pengembangan jaringan baru yang berbasis sistem voucher. Berikut kebutuhan perangkat keras dalam implementasi sistem voucher meliputi Kabel UTP Cat 5e, Crimping Tools, Router Mikrotik RB951Ui-2HND, dan Access Point D-Link DIR612. Tabel pembagian IP address jaringan lama dan baru PT. Tunggul Sakti Sejahtera terdapat dalam tabel 1

Tabel 1 Pembagian IP address jaringan lama dan baru

\begin{tabular}{|l|l|l|}
\hline Perangkat & \multicolumn{2}{|c|}{ IP } \\
\hline $\begin{array}{l}\text { Modem } \\
\text { ZTE F660 }\end{array}$ & \multicolumn{2}{|l|}{$192.192 .77 .2 / 24$} \\
\hline $\begin{array}{l}\text { modem } \\
\text { ISP2 }\end{array}$ & $192.192 .55 .2 / 24$ \\
\hline $\begin{array}{l}\text { Mikrotik } \\
\text { RB951ui- } \\
\text { 2hnd }\end{array}$ & ether1-ISP1 & $192.192 .77 .1 / 24$ \\
\cline { 2 - 3 } & ether2-ISP2 & $192.192 .55 .1 / 24$ \\
\cline { 2 - 3 } & ether3-LAN & $192.168 .77 .1 / 24$ \\
\cline { 2 - 3 } & ether4-wifi & $192.168 .55 .1 / 27$ \\
\hline $\begin{array}{l}|l| \\
\text { D-Link } \\
\text { DIR612 }\end{array}$ & \multicolumn{2}{|l|}{$\mid$} \\
\hline
\end{tabular}

Pembagian Ip address jaringan lama dan baru pada tabel 1 memiliki beberapa network yang diimlementasikan, modem ISP 1 terkoneksi dengan router Mikrotik memiliki network 192.192.77.0/24. Modem ISP 2 terkoneksi dengan router Mikrotik memiliki network 192.192.55.0/24. Untuk LAN pada router menggunakan network 192.168.77.0/24 dan network Wifi router 192.168.55.0/27. Tabel konfigurasi router Mikrotik terdapat pada tabel 2

Tabel 2 Konfigurasi router Mikrotik

\begin{tabular}{|l|l|l|l|}
\hline $\begin{array}{l}\text { Perangk } \\
\text { at }\end{array}$ & \multicolumn{3}{|c|}{ konfigurasi } \\
\hline $\begin{array}{l}\text { Router } \\
\text { board } \\
\text { RB951ui } \\
\text {-2hnd }\end{array}$ & $\begin{array}{l}\text { ip } \\
\text { address }\end{array}$ & $\begin{array}{l}\text { add } \\
\text { address }\end{array}$ & $192.168 .55 .1 / 27$ \\
\cline { 2 - 4 } & ip pool & range & $\begin{array}{l}192.168 .55 .3- \\
192.168 .55 .30\end{array}$ \\
\cline { 2 - 4 } & $\begin{array}{l}\text { ip } \\
\text { dhcp- } \\
\end{array}$ & $\begin{array}{l}\text { add } \\
\text { address }\end{array}$ & $192.168 .55 .0 / 27$ \\
\cline { 3 - 4 } & & \\
\cline { 3 - 4 } & & &
\end{tabular}

\begin{tabular}{|c|c|c|c|}
\hline Perangk & \multicolumn{3}{|c|}{ konfigurasi } \\
\hline & \multirow[t]{2}{*}{$\begin{array}{l}\text { networ } \\
\mathrm{k}\end{array}$} & & \\
\hline & & $\begin{array}{l}\text { gatewa } \\
\text { y }\end{array}$ & 192.168 .55 .1 \\
\hline & $\begin{array}{l}\text { system } \\
\text { ntp- } \\
\text { client }\end{array}$ & $\begin{array}{l}\text { primar } \\
y-n t p\end{array}$ & 152.118 .24 .8 \\
\hline & $\begin{array}{l}\text { system } \\
\text { clock }\end{array}$ & print & \\
\hline & \multirow[t]{2}{*}{$\begin{array}{l}\text { ip } \\
\text { hotspot } \\
\text { profile }\end{array}$} & $\begin{array}{l}\text { hotspot } \\
- \\
\text { address } \\
\end{array}$ & 192.168 .55 .1 \\
\hline & & $\begin{array}{l}\text { dns- } \\
\text { name }\end{array}$ & $\begin{array}{l}\text { hotspot.tunggulsakti. } \\
\text { com }\end{array}$ \\
\hline & radius & address & 127.0 .0 .1 \\
\hline \multirow[t]{15}{*}{$\begin{array}{l}\text { web } \\
\text { config } \\
\text { userman } \\
\text { RB951ui } \\
\text {-2hnd }\end{array}$} & $\begin{array}{l}\text { user- } \\
\text { manag } \\
\text { er } \\
\text { router }\end{array}$ & $\begin{array}{l}\text { ip- } \\
\text { address }\end{array}$ & 127.0 .0 .1 \\
\hline & \multirow{14}{*}{$\begin{array}{l}\text { user- } \\
\text { manag } \\
\text { er } \\
\text { profile }\end{array}$} & name & karyawan \\
\hline & & validity & $30 d(4 w 2 d)$ \\
\hline & & periode & $\begin{array}{l}\text { Monday, Tuesday, } \\
\text { Wednesday, thusday, } \\
\text { Friday, Saturday }\end{array}$ \\
\hline & & time & 11:30:00-13:30:00 \\
\hline & & $\begin{array}{l}\text { rate } \\
\text { limit }\end{array}$ & $512 \mathrm{k}$ \\
\hline & & name & $\mathrm{spv}$ \\
\hline & & validity & $30 d(4 w 2 d)$ \\
\hline & & periode & $\begin{array}{l}\text { Monday, Tuesday, } \\
\text { Wednesday, thusday, } \\
\text { Friday, Saturday }\end{array}$ \\
\hline & & time & 07:00:00-23:00:00 \\
\hline & & $\begin{array}{l}\text { rate- } \\
\text { limit }\end{array}$ & $1 \mathrm{M}$ \\
\hline & & name & sales \\
\hline & & validity & $2 w$ \\
\hline & & periode & $\begin{array}{l}\text { Monday, Tuesday, } \\
\text { Wednesday, thusday, } \\
\text { Friday, Saturday, } \\
\text { Sunday }\end{array}$ \\
\hline & & $\begin{array}{l}\text { rate- } \\
\text { limit }\end{array}$ & $2 \mathrm{M}$ \\
\hline
\end{tabular}

Konfigurasi router Mikrotik pada tabel 2 memiliki beberapa tahapan dari menambah IP address hingga konfigurasi tipe pengguna. Dengan konfigurasi IP address 192.168.55.1/27, network 192.168.55.0 dan pool 192.168.55.3192.168.55.30. Pada hotspot konfigurasi DNS name menggunakan hotspot.tunggulsakti.com dengan address 192.168.55.1. konfiurasi radius dan usermanager router menggunakan ip lokal 
Pengembangan Rekayasa dan Teknologi, Vol 15, No. 2, Desember 2019, pp 118-123

p-ISSN: $1410-9840 \&$ e-ISSN: $2580-8850$

http://journals.usm.ac.id/index.php/jprt/index

127.0.0.1 karena database berada pada router tersebut. Tabel konfigurasi access point terdapat pada tabel 3 .

Tabel 3 Konfigurasi Access Point

\begin{tabular}{|c|c|c|c|}
\hline Perangkat & \multicolumn{3}{|c|}{ konfigurasi } \\
\hline \multirow{8}{*}{$\begin{array}{l}\text { D-Link } \\
\text { DIR } 612\end{array}$} & \multirow{3}{*}{$\begin{array}{l}\text { Setup, } \\
\text { Local } \\
\text { Network }\end{array}$} & IP Address & 192.168 .55 .2 \\
\hline & & Subnet Mask & 255.255 .255 .224 \\
\hline & & DHCP Mode & none \\
\hline & \multirow{5}{*}{$\begin{array}{l}\text { Wireless, } \\
\text { Wireless } \\
\text { Basic }\end{array}$} & Enable SSID & yes \\
\hline & & Name (SSID) & $\begin{array}{l}\text { Tunggul Sakti- } \\
\text { Office }\end{array}$ \\
\hline & & Mode & $802.11 \mathrm{~b} / \mathrm{g} / \mathrm{n}$ \\
\hline & & channel & auto \\
\hline & & band width & auto \\
\hline
\end{tabular}

Konfigurasi access point pada tabel 3 memiliki IP address 192.168.55.2/27 dengan SSID Tunggul Sakti-Office. Tabel pengaturan hak akses internet karyawan terdapat pada tabel 4.

Tabel 4 Pengaturan hak akses internet karyawan

\begin{tabular}{|c|c|c|}
\hline Profile & \multicolumn{2}{|c|}{ Hak akses } \\
\hline \multirow[t]{6}{*}{ Karyawan } & $\begin{array}{l}\text { validitas voucher } \\
\text { (hari) }\end{array}$ & 30 hari $(4 w 2 d)$ \\
\hline & periode hari & Senin s.d Sabtu \\
\hline & jam akses & 11:30:00-13:30:00 \\
\hline & jumlah waktu akses & 26 jam \\
\hline & kecepatan akses & $512 \mathrm{kbps}$ \\
\hline & $\begin{array}{l}\text { larangan akses } \\
\text { website }\end{array}$ & $\begin{array}{l}\text { (youtube, } \\
\text { facebook, } \\
\text { instagram, twitter) }\end{array}$ \\
\hline \multirow[t]{6}{*}{ spv } & $\begin{array}{l}\text { validitas voucher } \\
\text { (hari) }\end{array}$ & $30 d(4 w 2 d)$ \\
\hline & periode hari & Senin s.d Sabtu \\
\hline & jam akses & 07:00:00-23:00:00 \\
\hline & jumlah waktu akses & 312 jam \\
\hline & kecepatan akses & $1 \mathrm{Mbps}$ \\
\hline & $\begin{array}{l}\text { larangan akses } \\
\text { website }\end{array}$ & $\begin{array}{l}\text { (youtube, } \\
\text { facebook, } \\
\text { instagram, twitter) }\end{array}$ \\
\hline \multirow[t]{3}{*}{ Sales } & $\begin{array}{l}\text { validitas voucher } \\
\text { (hari) }\end{array}$ & 2 minggu $(2 w)$ \\
\hline & periode hari & Setiap hari \\
\hline & kecepatan akses & $2 \mathrm{Mbps}$ \\
\hline
\end{tabular}

Pengaturan hak akses pada tabel 4 memiliki 3 kategori yaitu karyawan, spv dan sales. Masing- masing kategori memiliki ketentuan berbeda disesuaikan dengan kebutuhan perusahaan.

\section{Design}

Pada tahap ini, peneliti melakukan desain topologi jaringan dan peneliti menyiapkan rencana instalasi jaringan sesuai dengan kebutuhan dan desain topologi jaringan yang sudah disiapkan. Perancangan topologi fisik pada arsitektur jaringan terdapat pada gambar 4

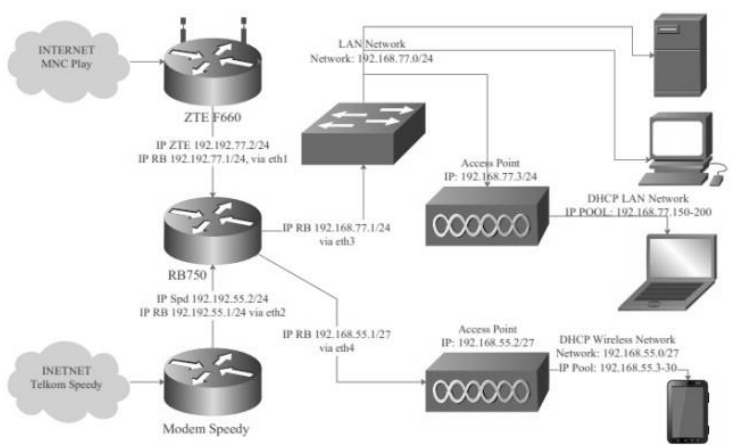

Gambar 3 Perancangan topologi fisik

Perancangan topologi fisik pada gambar 3 memiliki tambahan tarikan pada akses smartphone menggunakan access point tersambung dengan router Mikrotik. Memiliki network 192.168.55.0/27 dengan IP address access point 192.168.55.2 dan memiliki IP pool 192.168.55.3-192.168.55.30. Perancangan topologi logic pada arsitektur jaringan dapat dilihat dalam gambar 5

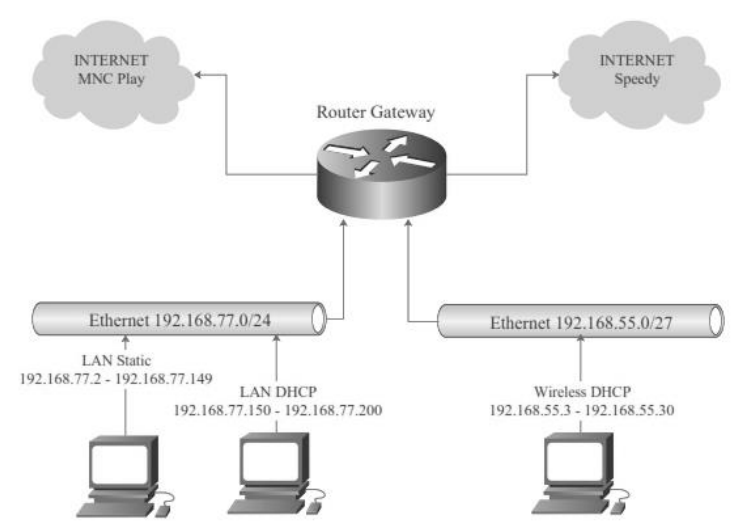

Gambar 4 Perancangan topologi logic

Perancangan topologi logic pada gambar 4 memiliki 2 network IP, yaitu 192.168.77.0/24 dan 192.18.55.0/27. Koneksi internet menggunakan 2 ISP, melalui MNCPlay dan Speedy. 
Pengembangan Rekayasa dan Teknologi, Vol 15, No. 2, Desember 2019, pp 118-123

p-ISSN: $1410-9840 \&$ e-ISSN: $2580-8850$

http://journals.usm.ac.id/index.php/jprt/index

\section{Implement}

Peneliti memulai instalasi secara fisik yaitu pengecekan instalasi pengkabelan yang sudah ada pada PT. Tunggul Sakti Sejahtera. Setelah memastikan konfigurasi kabel sudah sesuai dengan desain kemudian peneliti melakukan konfigurasi sistem voucher pada router Mikrotik terdapat pada gambar 5

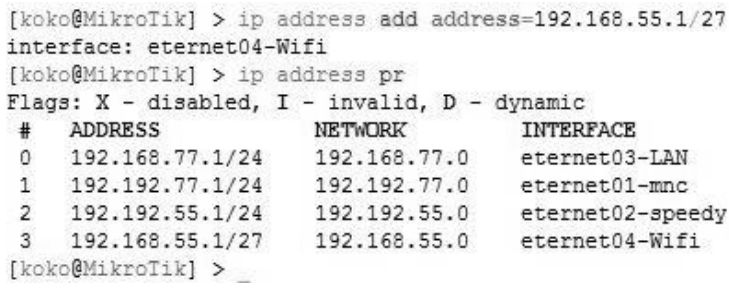

Gambar 5 Konfigurasi IP address router Mikrotik

Konfigurasi IP address router Mikrotik pada gambar 5 memiliki IP address berbeda pada tiap network. Pada interface ethernet04Wifi menggunakan network 192.168.55.0 dengan IP address 192.168.55.1/27. Konfigurasi router Mikrotik selanjutnya terdapat pada gambar 6

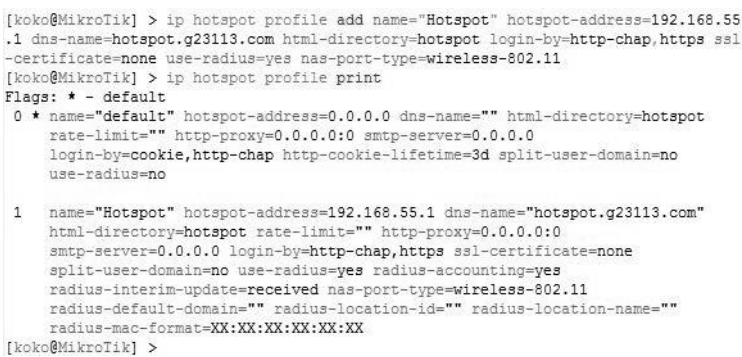

Gambar 6 Konfigurasi hotspot router Mikrotik

Konfigurasi hotspot router Mikrotik pada gambar 6 memiliki SSID hotspot.tunggulsakti.com dengan IP address 192.168.55.1 dan pada konfigurasi radius pilih yes. Konfigurasi router selanjutnya terdapat pada gambar 7

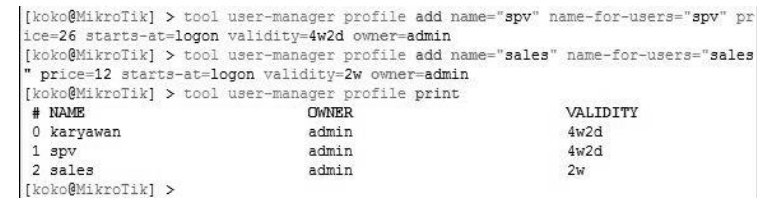

Gambar 7 Konfigurasi profile router Mikrotik

Pada konfigurasi profile router Mikrotik pada gambar 7 memiliki 3 kategori yaitu karyawan, spv dan sales. Setiap kategori memiliki validitas waktu berbeda sesuai kebutuhan perusahaan.

\section{Operate}

Pada tahap operasional peneliti melakukan kegiatan pengamatan pada jaringan komputer PT. Tunggul Sakti Sejahtera. Dalam pengamatan tersebut, peneliti memastikan bahwa pengguna jaringan internet sudah menggunakan sistem voucher sesuai kebutuhan. Tampilan voucher terdapat pada gambar 8

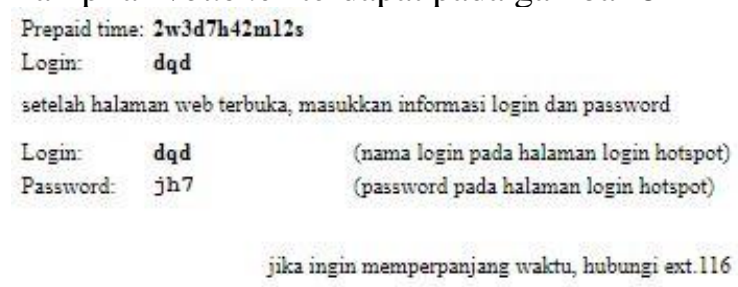

Gambar 8 Voucher akses internet

Tampilan voucher pada gambar 8 berisi informasi jangka waktu akses, login dan password pengguna akses internet PT. Tunggul Sakti Sejahtera.

Tampilan halaman login untuk mengisikan kode voucher terdapat pada gambar 9

http://hotspot.tunggulsakti.com/login?...
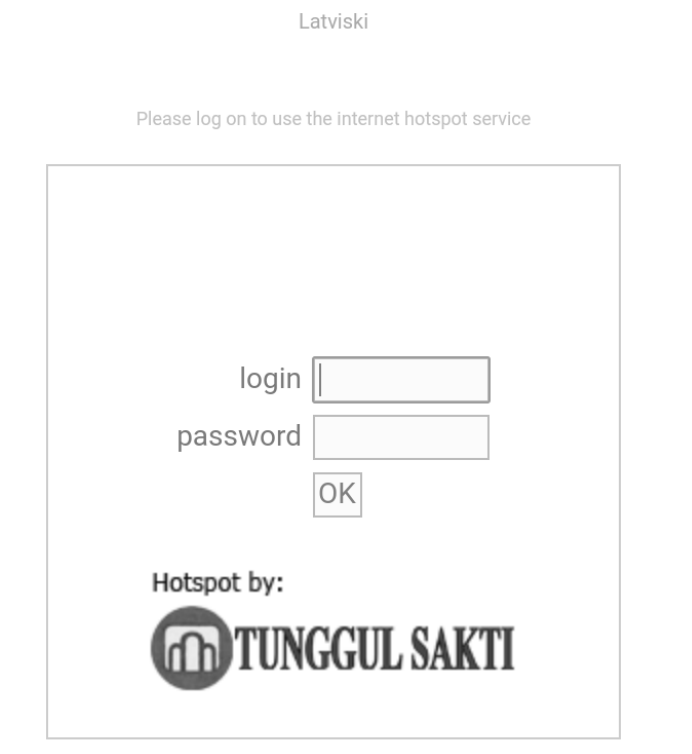

Gambar 9 Halaman login hotspot Tunggul Sakti

Halaman login hotspot Tunggul Sakti pada gambar 9 berisi form login dan password untuk diisi oleh pengguna akses internet.

Kegiatan pengamatan pada jaringan akses internet dapat di pantau pada session terdapat pada gambar 10 


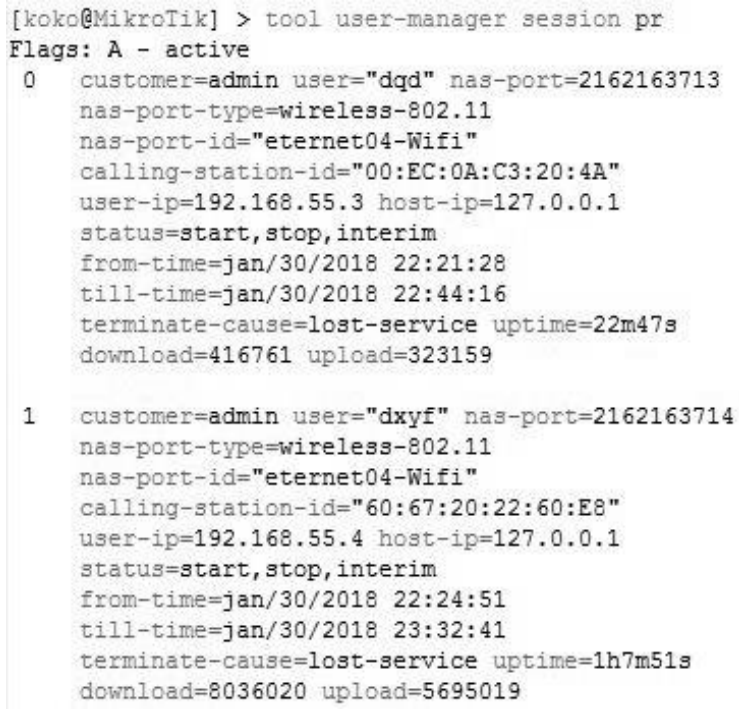

1 customer=admin user $=" \mathrm{dxyf}$ " nas-port $=2162163714$ nas-port-type=wireless -802.11

Gambar 10 Halaman aktifitas login pengguna

Halaman aktifitas login pengguna dipantau oleh administrator melalui session. Pada pemantauan di ketahui informasi pengguna aktif telah mengakses internet selama kurung waktu tertentu dan melihat mac address perangkat yang digunakan pada sistem voucher.

\section{Optimize}

Pada tahap ini peneliti memprediksi dan meminimalisir masalah dan kegagalan yang akan terjadi pada jaringan. Tahap optimisasi juga dapat merancang ulang jaringan jika terlalu banyak masalah dan kesalahan jaringan yang muncul sesuai kebutuhan. Berikut adalah hasil dan implementasi system voucher pada PT. Tunggul Sakti Sejahtera terdapat pada gambar 11
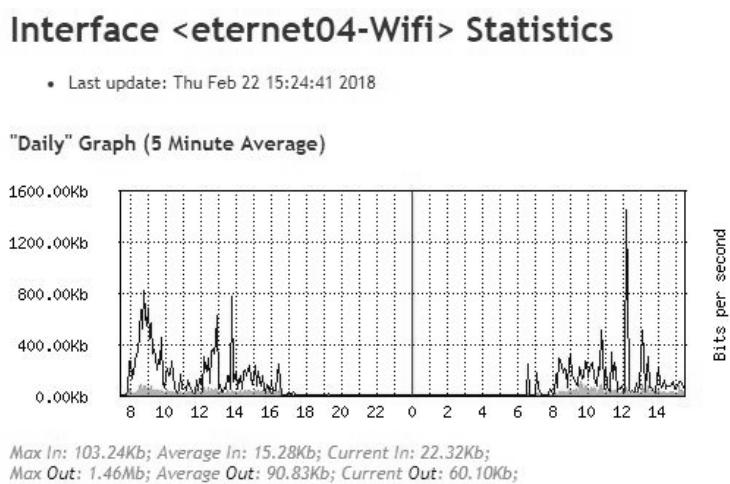

Gambar 11 Grafik akses internet sistem voucher

Grafik akses internet sistem voucher terlihat waktu akses dan kecepatan akses pada sistem voucher router Mikrotik. Terlihat akses internet dilakukan pada saat jam kerja dimulai pukul 07.00 hingga pukul 17.00 dengan kecepatan akses yang beragam.

\section{KESIMPULAN}

Dalam jurnal ini dapat diambil kesimpulan implementasi sistem voucher meningkatkan pengelolaan akses internet sesuai kebutuhan perusahaan sehingga karyawan mendapat fasilitas akses internet sesuai prioritas masing- masing dan pembagian akses internet yang sudah merata sesuai kebutuhan perusahaan berdampak internet menjadi lebih stabil.

Setelah melakukan implementasi sistem voucher peneliti menyarankan dokumentasi konfigurasi sistem dilakukan secara berkala dan pemakaian perangkat untuk memenuhi kebutuhan SOHO (Small Office Home Office), apabila kebutuhan menikat maka perlu melakukan upgrade.

\section{DAFTAR PUSTAKA}

[1] Agil Rakhmansyah, Pengaruh Penggunaan Teknologi Informasi Terhadap Kinerja (Studi Pada Karyawan Pt. Pln Area Madiun), Journal Administrasi Bisnis, Vol 14, no 1 (2014)

[2] Vikas Sharma, Vikram Kumar, Balvir Singh Thakur, 2011, Need Of Bandwidth Management And Formulation Of Policy Framework For Effective Utilisation Of internet Services Within a University Campus, International Journal of Computer Science and Communication. Vol 2 No.1 January-June 2011, pp. 173-178

[3] Didi Susianto, Iis Yulianti, Mengamankan Wireless dengan Menggunakan Two Factor, Password dan Mac Address Filtering, Jurnal Expert, http://jurnal.ubl.ac.id/index.php/expert/ar ticle/view/720

[4] Zainal Arifin, 2012, Sistem Pengamanan Jaringan Wireless, Andi Publisher, Yogyakarta.

[5] WILKINS, S., 2011, Cisco's PPDIOO Network Cycle, Cisco Press, http:// www.ciscopress.com/articles/article.asp? $\mathrm{p}=1697888$ 